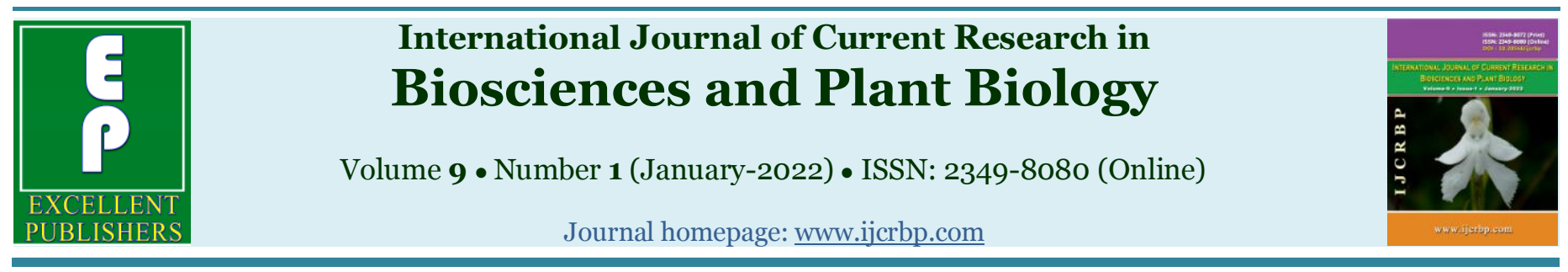

Original Research Article

doi: https://doi.org/10.20546/ijcrbp.2022.901.004

\title{
Structure and genetic diversity of two populations of Garcinia kola Heckel (Clusiaceae) revealed by RAPD markers
}

\section{Kouamé Kévin KOFFI, Any Olivier KOMENAN@*, KOUDOUGNON Alice Estère GOBA, Bi Irié Arsène ZORO}

\author{
University Nangui Abrogoua, Production Vegetale Research Unit, Genetics Laboratory, \\ 02 BP 801 Abidjan 02, Côte d'Ivoire \\ *Corresponding author; e-mail: olivierkomenan@gmail.com
}

\begin{tabular}{|c|c|}
\hline Article Info & Abstract \\
\hline $\begin{array}{l}\text { Keywords: } \\
\text { Conservation } \\
\text { Garcinia kola } \\
\text { Genetic diversity } \\
\text { Molecular biology } \\
\text { Sustainable } \\
\text { management }\end{array}$ & $\begin{array}{l}\text { This study aims to characterize the genetic diversity of two populations of Garcinia kola using five } \\
\text { RAPD markers in order to contribute to the development of sustainable management and conservation } \\
\text { strategy for this species. Genomic Deoxyribonucleic acid (DNA) extracted from leaf fragments of } 94 \\
\text { trees from two agroecological (south and west) zones according to Cethyl Trimethyl Ammonium } \\
\text { Bromide (CTAB) protocol was analyzed. The mean number of alleles was ranged from } 14.2 \text { to } 21.2 \\
\text { and the effective number of alleles ranged from } 8.62 \text { to } 9.44 \text {. The average Shannon diversity index was } \\
\text { ranged from } 2.08 \text { to } 2.59 \text { and the average genetic diversity was estimated to be } 0.80 \text {. A total of } 58 \\
\text { polymorphic bands were identified with a polymorphism rate of } 100 \% \text {. According to analysis of } \\
\text { molecular variance the most important component of the genetic variation was obtained within } \\
\text { population ( } 94 \% \text { ). The analysis of the genetic diversity of all the trees revealed the existence of two } \\
\text { groups composed of the trees from the two populations. In addition, genetic differentiation between the } \\
\text { two populations was relatively moderate (Fst }=0.061 \text { ). Sustainable management of } G \text {. kola trees } \\
\text { should be achieved through in situ conservation. But for ex situ conservation it would be more } \\
\text { practical to take as many individuals as possible within populations. }\end{array}$ \\
\hline
\end{tabular}

- Received: 4 November 2021 • Revised: 31 December 2021 • Accepted: 2 January 2022 • Published Online: 6 January 2022

\section{Introduction}

Garcinia kola tree is subject to permanent anthropogenic pressure because it is multipurpose use. Seeds, roots, bark, branches and wood of this tree are used in traditional medicine and food (Guedje and Fankap 2001). In addition, the plant has a market value both inside and outside Côte d'Ivoire (Koffi et al., 2015). The economic value of seeds fluctuates from
2.00 to 6.00 USD per kilogram (Kouamé et al., 2016). Thus, G. kola is a source of income diversification and contributes to improving the well-being of rural and urban populations.

However, excessive demands on G. kola, compared to the natural rate of regeneration, lead to the exhaustion of the resource. As a result, G. kola is classified as vulnerable species by the International Union for 
Conservation of Nature (Cheek 2004). So, this species requires a rational management. For that purpose, knowledge of the genetic organization of the species is required to meet sustainable management objectives identified as a national and international priority. The study of genetic diversity has the advantage of contributing to the advancement of conservation biology, population and community ecology. Population genetics provides estimators of genetic parameters that provide information on effective population size, gene flow, or differentiated gene pools (Diniz-Filho and De Campos-Telles, 2002) for the development of short- and long-term management strategy (Song et al., 2005; Watts et al., 2005).

A better understanding of genetic variability requires the use of molecular markers. Indeed, these markers are focused on the DNA molecule itself and are considered objective measures of variability. They are not subject to environmental influences (Vicente and Fulton 2003). On the other hand, the molecular markers used to study plant genetic diversity are of various types, among them Random Amplified Polymorphic DNA (RAPD). RAPD markers have received a lot of attention from geneticians for their simplicity and rapidity in revealing DNA variation.

Olawuyi and Azeez (2019) in Nigeria used six RAPD markers to assess the diversity of $25 \mathrm{G}$. kola accessions. RAPD markers have been successfully used to study genetic variation in Garcinia cambogia, G. cowa, G. hombroniana, G. indica, $G$. mangostana, and $G$. xanthochymus (Utpala et al., 2013; Tharachand et al., 2015). However, to our knowledge, no molecular studies have been conducted on G. kola in Côte d'Ivoire. RAPD markers were used in this study (i) to assess the genetic diversity of G. kola trees from two agroecological zones in Côte d'Ivoire. This study of the genetic diversity of G. kola is conducted (ii) to provide reliable data on the variability and genetic structure of this species. It will help (iii) to develop a management strategy and conservation of the species' resources in Côte d'Ivoire.

\section{Materials and methods}

\section{Study location and sources of materials}

The study was carried out at the genetic laboratory of Nangui Abrogoua University. Leaf samples from of 94 trees were collected from two agro ecological zones,
Biankouma (west) and Affery (south). Three fresh leaves were collected from the first branch of each tree. In the field, the collected leaves were stored in envelopes containing silica grains. At the Laboratory, these leaves were subsequently dried in a desiccator.

\section{Methods of genetic analysis}

\section{DNA extraction and purification}

DNA extractions were made on dried leaves in desiccator. It was extracted using CTAB method according to the protocol of Doyle and Doyle (1987) with modifications. For each tree, $1 \mathrm{~g}$ of leaf was crushed and transferred to a $1.5 \mathrm{~mL}$ Eppendorf tube containing $700 \mu \mathrm{L}$ of preheated CTAB (20 mM EDTA, $0.1 \mathrm{M}$ Tris- $\mathrm{HCl}, \mathrm{pH} 8.0,1.4 \mathrm{M} \mathrm{NaCl}$, and $0.4 \% \beta-$ mercaptoethanol). The mixture was incubated at $65^{\circ} \mathrm{C}$ for $45 \mathrm{~min}$ in a water bath and vortexed every $15 \mathrm{~min}$. Subsequently, $800 \mu \mathrm{L}$ of alcohol-isoanyl chloroform was added to each tube and mixed by inversion and centrifuge at 14,000 rpm for $15 \mathrm{~min}$. After this step, 500 $\mu \mathrm{L}$ of the supernatant was recovered in new Eppendorf tubes. Then $500 \mu \mathrm{L}$ of chloroform were added back into each tube and mixed by inversion. The mixture was centrifuged at $14,000 \mathrm{rpm}$ for 15 minutes. This procedure was performed one last time with $350 \mu \mathrm{L}$ of the supernatant and chloroform each, a mixture equivalent to $700 \mu \mathrm{L}$. Subsequently, $100 \mu \mathrm{L}$ of the supernatant was recovered in new Eppendorf tubes, in which $200 \mu \mathrm{L}$ of isopropanol were added and mixed by inversion. The mixture was placed at $-20^{\circ} \mathrm{C}$ for 1 hour, then centrifuged at 13,000 rpm for $10 \mathrm{~min}$. After this step, the cap was recovered and $300 \mu \mathrm{L}$ of $70 \%$ alcohol was added and the mixture was centrifuged at 13,000 rpm for 5 minutes. This step has been completed twice. The pellets were then collected and dried at room temperature. In each tube containing the cap, the mixture of $100 \mu \mathrm{L}$ of $0.1 \times \mathrm{TE}$ and $3 \mu \mathrm{L}$ of RNase was added and incubated at $37^{\circ} \mathrm{C}$ for 2 hours. The purified DNA was stored at $-20^{\circ} \mathrm{C}$.

\section{DNA quality and quantity assessment}

The quality and quantity of the DNA are essential for good amplification by PCR. Quantification was performed by measuring the concentration of DNA extracts. This operation was performed with the Nanodrop on which $1 \mu \mathrm{L}$ of each extracted DNA sample was deposited. DNA purity was evaluated with Nanodrop and agarose gel electrophoresis. The 
presence of clear bands indicates the presence and good quality of DNA, whereas the trails correspond to degraded DNA. In the latter case, new extractions were made to replace extract judged poor quality DNA. The purity of the extracted DNA was assessed by the DO260/DO280 ratio. If the ratio is between 1.8 and 2, the DNA is said to be pure. When this ratio is greater than 2, the DNA is considered to be contaminated with RNA. On the other hand, if the ratio is less than 1.8 the DNA is considered to be contaminated by proteins.

\section{Screening of RAPD primers}

The choice of primers was made arbitrarily. However, two basic criteria defined by Williams et al. (1990) for the selection of RAPD markers were used: a minimum of $40 \%$ GC (the GC content is usually $50-80 \%$ ) and the absence of palindromic sequence (the same nucleic acid sequence when read in both directions, 5 " $\rightarrow 3$ " and 3" $\rightarrow 5$ "). The G-C bond consists of three hydrogen bonds and the A-T bond of only two. A primer-DNA hybrid with less than $50 \%$ GC is unlikely to withstand the temperature of DNA stretching $\left(72^{\circ} \mathrm{C}\right)$ by DNA polymerase. Seven RAPD primers were used for initial screening, out of which 5 primers were found to be suitable for amplification. All the primers were decamers.

\section{DNA amplification by PCR}

Polymerase Chain Reaction (PCR) was an in vitro amplification method that exponentially amplifies the amount of a target DNA fragment by repeating elongation reactions with DNA polymerase. The PCRs were carried out in 96 well plates. The final volume of $30 \mu \mathrm{L}$ per sample consisted of $5 \mu \mathrm{L}$ of matrix DNA and $25 \mu \mathrm{L}$ of PCR mix. The PCR mix consisted of $0.25 \mu \mathrm{L}$ Taq polymerase $[5 \mathrm{u} / \mu \mathrm{L}]$ (PROMEGA, Madison, WI USA), $\quad 0.3 \mu \mathrm{L}$ primer $[20 \mathrm{mM}], \quad 0.5 \quad \mu \mathrm{L}$ deoxyribonucleotide (dNTP) at $10 \mathrm{mM}, 1.8 \mu \mathrm{L} \mathrm{Mgcl} 2$ [25mM], $3 \mu \mathrm{L}$ Buff coloured and uncoloured each and $16.14 \mu \mathrm{L}$ of sterile $\mathrm{H}_{2} \mathrm{O}$. The amplification program used was that of Goba et al. (2020) which includes a double amplification of 47 cycles. Amplification conditions were: first denaturation at $94^{\circ} \mathrm{C}$ for $4 \mathrm{~min}$ followed by 47 denaturation cycles at $93^{\circ} \mathrm{C}$ for $20 \mathrm{sec}$, hybridization at $36^{\circ} \mathrm{C}$ for $40 \mathrm{sec}$ and elongation at $72^{\circ} \mathrm{C}$ for $1 \mathrm{~min}$. The reaction ends with a final elongation phase at $72^{\circ} \mathrm{C}$ for $4 \mathrm{~min}$ and a cooling phase at $4^{\circ} \mathrm{C}$. The GeneAmp® PCR System 9700 (Applied Biosystems,
USA) thermocycler was used for all reactions. Amplifications were verified by visualizing the amplicons by $1 \%$ agarose gel electrophoresis at $100 \mathrm{~V}$ for 1 hour.

\section{Statistical analysis}

Statistical analyses were carried out using several software packages. These programs allow comparable and/or complementary results on the structure of genetic diversity at different scales. They also help to explain gene flow within and between populations and test genetic isolation by distance between populations.

From the gel images, the phenotype of each individual at each locus was recorded by the binary method, 1 when the band was present and 0 when the band was absent. These bands were considered polymorphic when absent from a sample at a frequency greater than $1 \%$ (Jorde et al., 1995). The data matrix generated for each population was then used to calculate conventional indices of diversity and genetic structure (Wright 1951; Nei 1987). Indices used to calculate intra-population diversity include percent polymorphic loci $(\mathrm{P})$ at the 95\% threshold; mean number of alleles per locus, which expresses allelic richness of loci $(\mathrm{Na})$; number of effective (Ne) alleles; and Nei (1987) indices of genetic diversity.

At the inter-population level, the structure and level of differentiation were analyzed at different levels, to highlight genetic variability. First, an analysis of molecular variance (AMOVA) was performed using GENALEX Version 6.5 Software to verify the level of inter and intra population variation. It is a hierarchical analysis of variance whose data are the genetic distances between individuals and whose hypotheses are tested by permutation tests. Then, the genetic differentiation of populations was addressed by calculating the Fst coefficient described by Wright (1951), corrected by Weir and Cockerham (1984) and tested by permutation (1000 permutations). A value of 0 for Fst indicates no genetic divergence within subpopulations and a value of 1 indicates complete divergence. Populations were considered to be poorly differentiated when Fst was less than or equal to 0.05. They are said to be moderately differentiated when Fst is between 0.05 and 0.15 . They are strongly differentiated for values $0.15<\mathrm{Fst} \leq 0.25$, and very strongly differentiated when Fst $>0.25$ (Mohammadi and Prasanna, 2003). 
Genetic relationships between G. kola populations were represented graphically using Principal Coordinates Analysis (PCoA). This multivariate analysis method allows to represent on a two- or three-dimensional graph, objects described by a matrix containing similarity indices between these objects (Gower, 1966). In this study, the principal coordinate analysis was performed with XLSTAT Version 2014.5.03, based on the genetic distance matrix between the different trees.

Population structure was visualized using a Bayesian approach implemented in STRUCTURE 2.3.4 (Pritchard et al., 2000). STRUCTURE uses a systematic Bayesian clustering approach by applying Monte Carlo Markov Chain (MCMC). The MCMC process begins by randomly assigning individuals to a predetermined number of groups, without a priori information on their membership in a population, then estimating frequency variants within each group and reassigning individuals based on these frequency estimates (Porras-Hurtado et al., 2013). This process is carried out based on simulations, repeated many times.

In this study, 11 simulations were performed for each $\mathrm{K}$ population value (K being unknown). Specifically, we chose the mixing model (admixture) and the option of correlated allele frequencies between populations, as this configuration is considered the best (Falush et al. 2003). Each population is characterized by its own allele frequencies at the analyzed loci. The Bayesian method will assign individuals to different populations based on their multilocus genotype (Pritchard et al., 2000; Falush et al., 2003). The range of $\mathrm{K}$ values tested ranged from 1 to $10(\mathrm{~K}=1$ to $\mathrm{K}=10)$. The calculation strings were conducted with an initial period of 10,000 burn-in iterations followed by 100,000 iterations. When alpha, the degree of mixing, is close to zero, individuals are considered to belong to a specific group, whereas alpha $>1$ means that individuals are mixed (Falush et al. 2003). All raw result files were imported into the online STRUCTURE HAVESTER program (Earl and vonHoldt, 2012) which directly calculated and graphically represented $\Delta K$. To determine the number of genetic groups represented in the sample, the second drift of the likelihood function $(\Delta \mathrm{K})$ was calculated using the method of Evanno et al., (2005). Here we are interested in the value marked by the large peak in the $\Delta \mathrm{K}$ statistic. This value defines the number of exact populations.

\section{Results}

\section{Marker polymorphism}

The polymorphic primers that generated multiple fragments (bands) was five out of the seven primers tested (Table 1). These were KFP03, KFP05, KFP07, KFP16 and KFP24.In the follow, these primers were used to study the diversity and genetic structure of 85 G. kola trees out of the original 94 samples. Nine individuals that did not produce reproducible bands had not been taken in count. In addition, the primers OPN06 and KFP02 were not retained because they did not amplify for one and did not produce reproducible bands for the other. The molecular weight of the amplified fragments ranged from 50 to 2000 base pairs. A total of 58 bands with an average of 11.6 bands per primer were observed. The number of polymorphic bands ranged from 10 to 13 (10 for KFP16, $11 \mathrm{KFP} 05,11$ for KFP24, and, 12 for KFP07 and 13 for KFP03). The polymorphism rate is $100 \%$. Amplification profiles of the diversity obtained with the KFP05 and KFP07 primers are shown in Fig. 1 and Fig. 2, respectively.

Table 1. Selected primers, percentage of polymorphism and size of fragments amplified by RAPD primers used in 94 Garcinia kola individuals.

\begin{tabular}{llllll}
\hline Primers & Sequence $\left(\mathbf{5}^{\prime} \rightarrow \mathbf{3}^{\prime}\right)$ & $\begin{array}{l}\text { Selected } \\
\text { primers }\end{array}$ & $\begin{array}{l}\text { Number of } \\
\text { polymorph bands }\end{array}$ & $\begin{array}{l}\text { Polymorphism } \\
\text { percentage }(\boldsymbol{\%})\end{array}$ & Band sizes $(\mathbf{p b})$ \\
\hline OPN 06 & GAG ACG CAC A & NO & - & - & - \\
KFP 02 & CGT CCG TCA G & NO & - & - & - \\
KFP 03 & GTT AGC GGC G & YES & 13 & 100 & $50-1300$ \\
KFP 05 & CCT GGC GAG C & YES & 12 & 100 & $100-1100$ \\
KFP 07 & CCA GGC GCA A & YES & 12 & 100 & $80-2000$ \\
KFP 16 & GCA TGG AGC T & YES & 10 & 100 & $200-1500$ \\
KFP 24 & ACT CGT AGC C & YES & 11 & 100 & $200-1500$ \\
Averages & & & 11,6 & 100 & \\
\hline
\end{tabular}




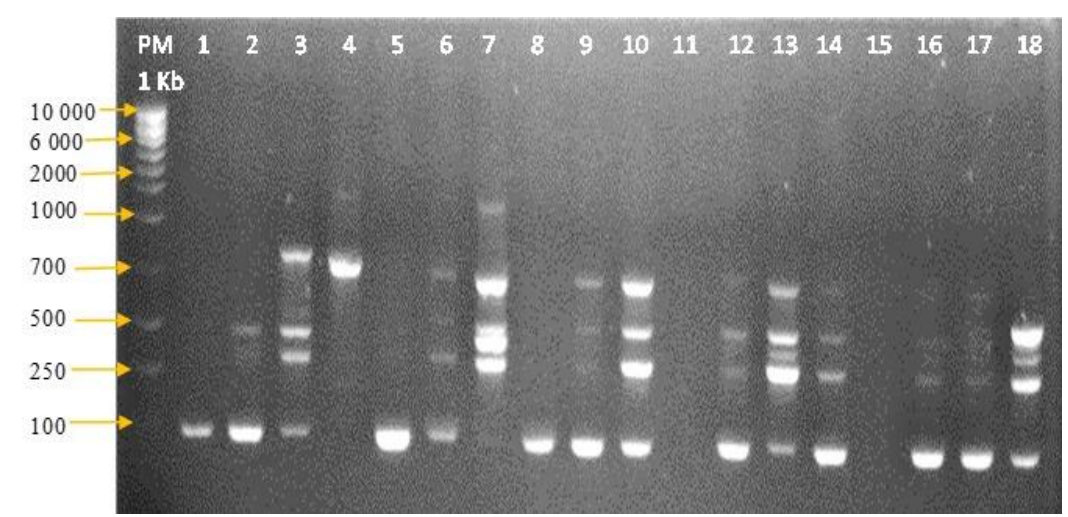

Fig. 1: Polymorphism (presence/absence) revealed by amplification of the KFP 05 primer in 18 Garcinia kola individuals. The PM channel indicates the molecular weight marker (Smart Ladder $1 \mathrm{~Kb}$ ). 1 to 18: DNA samples used.

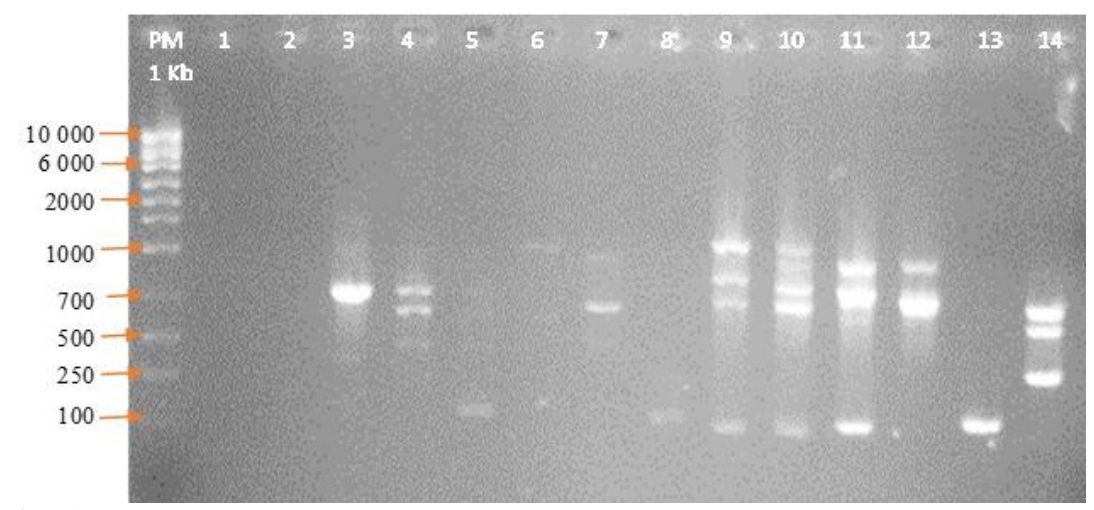

Fig. 2: Polymorphism (presence/absence) revealed by amplification of the KFP 07 primer in 14 Garcinia kola individuals. The PM channel indicates the molecular weight marker (Smart Ladder $1 \mathrm{~Kb}$ ). 1 to 14: DNA samples used.

\section{Intra-population genetic diversity}

From the matrix generated by the profile of the individuals analyzed, the genetic diversity indices were evaluated for each population in the collection areas. Results are presented in Table 2. The average number of alleles $(\mathrm{Na})$ was $21.2 \pm 1.68$ in Affery and $14.2 \pm 3.8$ in Biankouma with an average of $17.7 \pm 2.28$ for the entire population studied. The number of effective alleles $(\mathrm{Ne})$ was $8.62 \pm 0.89$ in Affery and $9.44 \pm 3.15$ in Biankouma. The diversity indices of Nei were $2.59 \pm 0.08$ in the Affery population and $2.08 \pm 0.049$ in the Biankouma population.

Table 2. Intra-population genetic diversity indices ( \pm standard deviation).

\begin{tabular}{llllll}
\hline Locations & $\boldsymbol{N}$ & $\boldsymbol{N a}$ & $\boldsymbol{N e}$ & $\boldsymbol{I}$ & $\boldsymbol{h}$ \\
\hline Affery & 54 & $21.2 \pm 1.68$ & $8.62 \pm 0.89$ & $2.59 \pm 0.08$ & $0.88 \pm 0.02$ \\
Biankouma & 31 & $14.2 \pm 3.8$ & $9.44 \pm 3.15$ & $2.08 \pm 0.49$ & $0.73 \pm 0.15$ \\
Averages & 42 & $17.7 \pm 2.28$ & $9.03 \pm 1.55$ & $2.33 \pm 0.25$ & $0.80 \pm 0.07$ \\
\hline
\end{tabular}

$N$ : sample size; $N a$ : number of alleles; $N e$ : number of effective alleles; I: Shannon diversity index $h$ : Nei diversity index.

\section{Inter-population genetic diversity}

The analysis of molecular variance (AMOVA) approach was explored to further analyze genetic structure within and between populations. The results of this analysis are reported in Table 3. It shows the distribution of genetic diversity in total and between populations. These results showed that $6 \%$ of the genetic variation was attributable 
to the difference between the two populations studied. Most of the genetic variation, 94\%, was found to be within populations $\left(\mathrm{F}_{S T}=0.939\right)$. Genetic differentiation among population and within the two populations were significantly different from zero with $\mathrm{P}=0.001$. Between sites, the value of the genetic differentiation coefficient $\mathrm{F}_{S T}=0.061$.

Table 3. Analysis of Molecular Variance (AMOVA) of two populations of Garcinia kola.

\begin{tabular}{lllllll}
\hline Sources & df & SSD & MS & \% variance & $\boldsymbol{F}_{\boldsymbol{S T}}$ & $\boldsymbol{P}$ \\
\hline Among populations & 1 & 7.519 & 7.519 & 6 & 0.061 & 0.001 \\
Within populations & 83 & 174.951 & 2.108 & 94 & 0.939 & 0.001 \\
Total & 84 & 182.470 & & 100 & & \\
\hline
\end{tabular}

df: degree of freedom; SSD: sum of squares of the deviations; MS: mean squares; Fst: coefficient of differentiation; $\boldsymbol{P}$ : probability associated with the estimated Fst value after 1000 resamples.

\section{Genetic relationships between populations}

Principal coordinate analysis (PCoA) was performed as a complement to analysis of molecular variance (AMOVA) to refine the understanding of the $\mathrm{F}_{S T}$ interpopulation diversity indices. This analysis was based on the genetic distances between trees. The first three axes of the PCoA were selected to analyze the relationships between all trees. They account for $21.65 \%$ of the total inertia. These axes encompass $9.76 \% 6.50 \%$ and $5.39 \%$ of the variation respectively. The projection of the 85 individuals in the plane defined by the first two axes (Fig. 3) shows a structuring of the trees into four groups. These different groups were composed of trees from both Biankouma and Affery. Group 1 contained only trees from the Affery population.

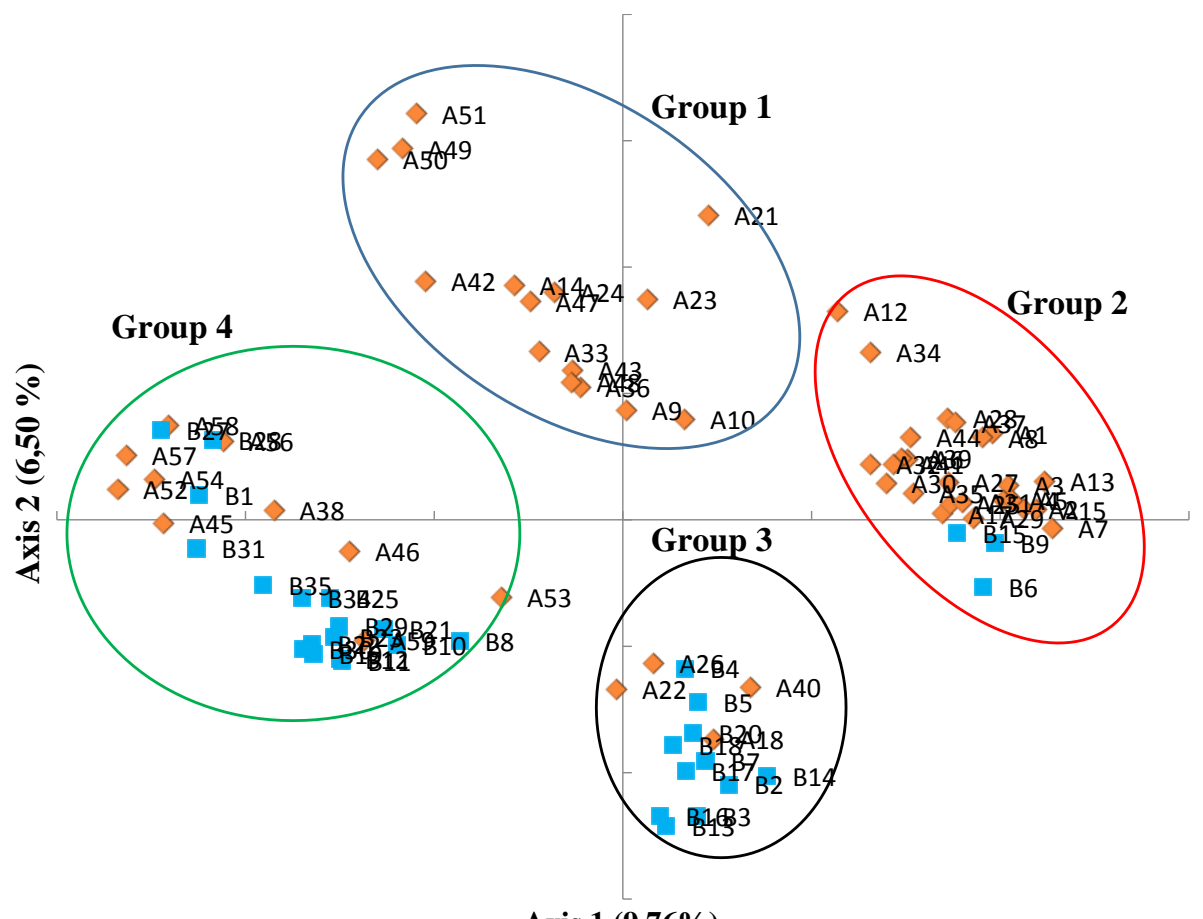

Axis 1 (9,76\%)

Fig. 3: Projection of the 85 Garcinia kola individuals on the plane 1-2 of the Principal Coordinate Analysis (PCoA) performed from the genetic distance matrix. The orange color represents the trees of Affery; the blue color represents the trees of Biankouma.

\section{Genetic relationships among trees}

A Bayesian clustering analysis was performed to determine groups of individuals from the two populations that are genetically homogeneous. Fig. 4 shows the values of the second-order change in loglikelihood $(\Delta \mathrm{K})$ for simulations ranging from 1 to 10 . This likelihood function showed a peak for $K=2$. Therefore, the optimal number of groups in the samples was two. Thus, based on a 55\% assignment probability, 
54 trees out of the 85 analyzed were assigned to both groups. The other 31 trees had coefficients of membership in both populations lower than 55\%. They were not assigned to any group because they were considered "unclassified" or "admixed", their genotype coming from recombination between several groups. Most of these trees shared alleles from subpopulations 1 and 2 in proportions ranging from $0.46 \%$ to $0.54 \%$. Analysis of the genotype assignment rate reveals that the identified genotypes were assigned with different proportions between the two groups (Table 4). The first group was composed of 16 trees, $37.14 \%$ of which came from the Affery site and $10.53 \%$ from the Biankouma site. The membership coefficient of the trees in this group varied from 0.561 to $0.659 \%$. The second group included 38 trees with $62.85 \%$ from Affery and $89.47 \%$ from Biankouma. These trees have a membership coefficient that varies between 0.55 and $0.749 \%$.

Table 4. Percentage of genotypes identified at the two geographic locations and assigned 55\% to the two groups defined at $\mathrm{K}=2$.

\begin{tabular}{lllllll}
\hline \multirow{2}{*}{ Locations } & \multirow{2}{*}{ Genotypes } & \multirow{2}{*}{ Genotypes selected } & Group 1 & \multicolumn{3}{c}{ Group 2 } \\
\cline { 5 - 7 } & & & Number & \% & Number & \% \\
\hline Affery (A) & 54 & 35 & 2 & 37.14 & 22 & 62.85 \\
Biankouma (B) & 31 & 19 & 16 & 10.53 & 17 & 89.47 \\
Total & 85 & 54 & 27.78 & 39 & 72.22 \\
\hline
\end{tabular}

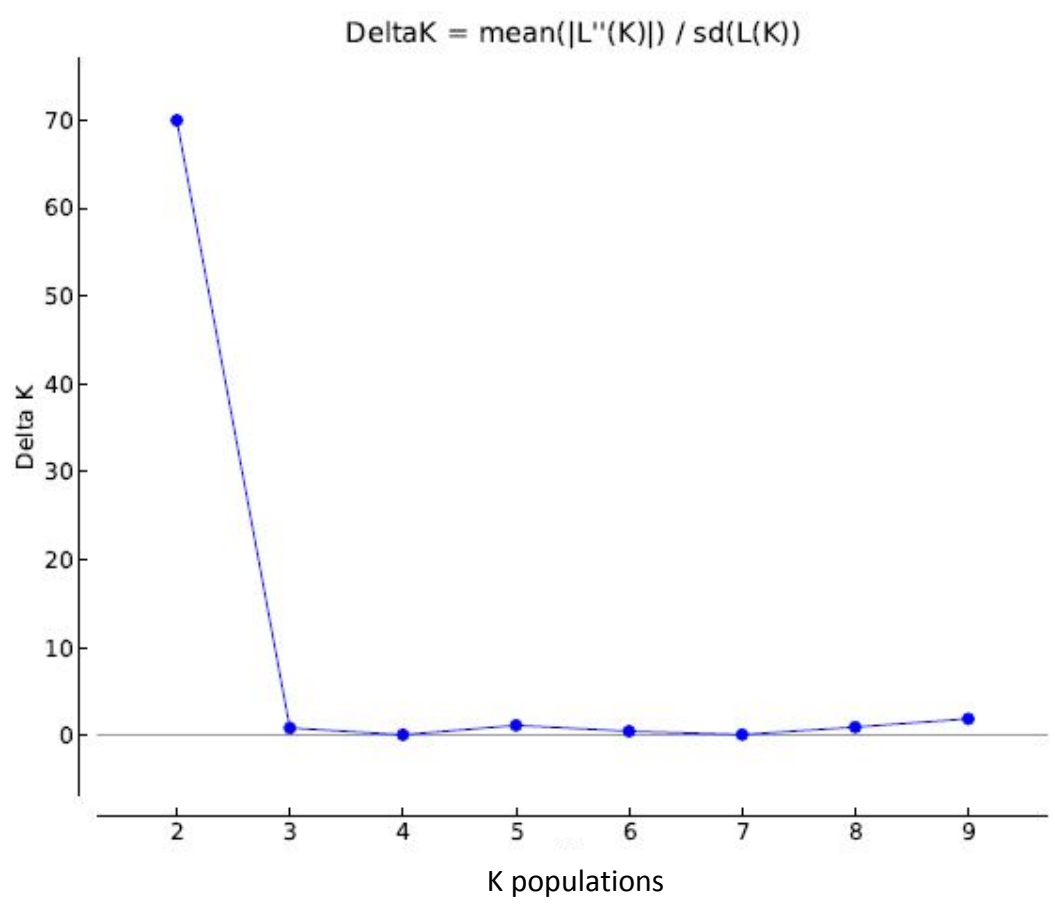

Fig. 4: Determination of the most likely value of $K$ according to the method of Evanno et al. (2005). K represents the number of groups (populations) formed.

\section{Discussion}

Assessment of genetic diversity and population structure of Garcinia kola in Côte d'Ivoire is important for management and conservation of this species. However, adequate genomic information on G. kola is not available to design specific markers (Seyit et al., 2010; Utpala et al., 2013). Five RAPD primers were used to two populations analyze. The percentage of primers used that produced interpretable profiles for genetic diversity analysis then seems to depend on the adaptability of the primers to the species studied (Goba et al., 2020) and the experimental conditions (Vroh et al., 1997). The five RAPD primers used in this study were found to be useful in analyzing the genetic diversity of G. kola. This result is consistent with the findings of Seyit et al, (2010) and Ojuederie et al, (2013) who indicated that RAPD markers can be 
effectively used to determine variation based on geographic or morphological features within a species. The polymorphisms revealed by the five decamer primers indicate that they are reliable tools for assessing genetic diversity in G. kola. A total of 58 polymorphic bands were obtained, which corresponds to $100 \%$ polymorphism. This polymorphism is much higher than those obtained from other woody species: $65.43 \%$ in Parkia biglobosa (Mimosaceae) (Amusa et al., 2014) and $62 \%$ in the almond tree Prunus dulcis (Rosaceae) (Kadri et al., 2006). Therefore, the use of these RAPD markers to study the genetic diversity of the two G. kola populations was founded.

The analysis of the genetic structure allows to understand the spatial organization of the diversity and to define strategies for its conservation (Emperaire et al., 2003). The coefficient of differentiation Fst $=0.061$ is average, indicating moderate genetic differentiation between the two populations (Wright, 1978). This value of the differentiation coefficient may be due to the small size of our sample, 94 trees (Kremer 1994). In addition, the high exploitation pressure on G. kola trees in their natural growing areas is a threat to the genetic diversity of the species and could threaten its development.

Analysis of Molecular variance (AMOVA), revealed that a large proportion of the variance $(94 \%)$ is attributable to variation between $G$. kola trees within each population while $6 \%$ of the total genetic diversity is expressed by allelic frequency variation between sites. These data are consistent with those of Kremer (1994) who, in a landmark study, defined that, on average, forest species express very high levels of intrapopulation diversity compared to other plants. Several previous studies on woody species, such as Argania spinosa (Sapotaceae) (Pakhrou et al., 2015), Populus tremuloides (Salicaceae) (Yeh et al., 1995), Araucaria araucana (Araucariaceae) (Bekessy et al., 2002), Eucalyptus microtheca (Myrtaceae) (Li, 2000), Pterocarpus erinaceus (Fabaceae) (Goba et al., 2020), agree with our results. G. kola populations with a high level of genetic variation are valuable, as they provide a diverse gene pool from which genetic conservation and breeding programs can be established. Furthermore, the high genetic variability within populations is thought to be due to the allogamous breeding mode of G. kola. Indeed, allogamous species generally maintain high intra-population genetic variation and low genetic differentiation between populations (Hamrick and Godt, 1997). The high intra-population variation observed at these sites suggests that intensive sampling within the two populations for reforestation or conservation would capture much of the diversity within the species. In situ conservation is useful for preserving existing diversity and facilitating the expression of traits in individuals. Furthermore, the low diversity between populations suggests that individuals belong to the same gene pool and that the observed morphological variability is an expression of environmental factors and tree age.

The genetic structure of the trees from both sites, using the Bayesian method, revealed two distinct genetic groups. Each group contains trees from both populations. This genetic structuring could be explained by the existence of a common genetic base between the two populations. The G. kola populations studied would belong to the same gene pool. Moreover, this level of diversity and genetic structure could be essentially the result of the adaptive history of the species and the action of man, which has limited the flow of genes among populations of this species in Côte d'Ivoire over time. These results open research perspectives about the domestication and genetic improvement of G. kola in Côte d'Ivoire.

\section{Conclusions}

The present study provided an understanding of the similarities and differences between G. kola trees within two populations. For this purpose, RAPD markers were used. Out of all five markers, a total of 58 polymorphic bands were identified with a polymorphism rate of $100 \%$. The results also showed that diversity structuring is $94 \%$ within populations while it is $6 \%$ between populations. These results confirm the high intrapopulation diversity common in cross-pollinated plants, including G. kola. Moreover, genetic differentiation between the two populations was relatively moderate $($ Fst $=0.061)$, so a larger number of trees should be collected to obtain maximum variability. However, this result shows a strong similarity between individuals of the two populations. Bayesian analysis of the genetic diversity of all trees revealed the existence of two groups composed of trees from both populations. This study suggests that the morphological diversity observed in the two populations is only related to the environment and that the trees of the two populations have a common genetic base. We recommended the introduction of G. kola in reforestation programs in Côte d'Ivoire for the conservation of this species. 


\section{Conflict of interest statement}

Authors declare that they have no conflict of interest.

\section{References}

Amusa, O., Adesoye, A., Ogunkanmi, A., Omoche, O., Olowe, O., Akinyosoye, S., Omodele, T., 2014. Genetic diversity of Parkia biglobosa from different agroecological zones of Nigeria using RAPD markers. Int. J. Biodiver., 2014: 457309.

Cheek, M., 2004. Garcinia kola. The IUCN Red List of Threatened species. e.T34715A9884648.

Diniz-Filho, J.A.F., De Campos-Telles, M.P., 2002. Spatial autocorrelation analysis and the identification of operational units for conservation in continuous populations. Conserv. Biol., 16(4): 924-935.

Doyle, J.J., Doyle, J.L., 1987. A rapid DNA isolation procedure for small quantities of fresh leaf tissue. Phytochem. Bull., 19: 11-15.

Earl, D.A., VonHoldt., B.M., 2012. STRUCTURE HARVESTER: A website and program for visualising STRUCTURE output and implementing the Evanno method. Conserv. Genet. Resour., 4(2): 359-361.

Emperaire, L., Gilda., S.M., Fleury, M., Robert, T., Mckey, D., Pujol, B., 2003. Approche comparative de la diversité génétique et de la diversité morphologique des maniocs en Amazonie (Brésil et Guyanes). Actes du BRG., 4: 247-267.

Evanno, G., Regnaut, Goudet, J., 2005. Detecting the number of clusters of individuals using the software Structure: a simulation study. Mol. Ecol., 14: 26112620.

Falush, D., Stephens, M., Pritchard, J.K., 2003. Inference of population structure using multilocus genotype data: linked loci and correlated allele frequencies. Genetics, 164(4): 1567-1587.

Goba, K.A.E., Kouonon, L.C., Koffi, K.G., Koffi, A., Tré, B.I.G., Sié, R.S., 2020. Molecular characterization of Pterocarpus erinaceus POIR. (Fabaceae) of Côte d'Ivoire using RAPD markers. Int. J. Curr. Res. Biosci. Plant Biol., 7(5): 13-23.

Gower, J.C., 1966. Some Distance Properties of Latent Root and Vector Methods Used in Multivariate Analysis. Biometrika, 53: 325-338.

Guedje, N.M., Fankap, R., 2001. Utilisations traditionnelles de Garcinia lucida et Garcinia kola (Clusiaceae) au Cameroun. Sys. Geogr. Pl., 71: 747758.
Hamrick, J.L., Godt, M.J.W., 1997. Allozyme diversity in cultivated crops. Crop Sci., 37(1): 26-30.

Jorde, L.B., 1995. Population Specific Genetic Markers and Diseases. In: Molecular Biology and Biotechnology: A Comprehensive Desk Reference (Ed.: Mayer, R.A.). VCH Publisher Inc., New York, USA, pp.724-728.

Kadri, K., Snoussi, H., Ben, N.M., Abdallah, B.A., 2006. Application de marqueurs moléculaires pour l'analyse de la diversité génétique chez l'amandier (Prunus dulcis Mill.). Cah. Agric., 15(2): 195-202.

Koffi, K.E., N'guessan, A.K., Kouamé, C.N., Kouassi, M.K., Kahia, J.W., 2015. Possibility of using the intermediate mature stage of Garcinia kola Heckel seeds to shorten the germination time. Afr. J. Agric. Res., 10(52): 4762-4769.

Kouamé, N.M.T., Aké, C.B., Mangara, A., N'guessan, K., 2016. Analyse de l'intérêt socio-économique des graines de Garcinia kola Heckel (Clusiaceae) dans la commune de Koumassi (Abidjan), Côte d'Ivoire. Int. J. Biol. Chem. Sci., 10(6): 25872595.

Kremer, A., 1994. Diversité génétique et variabilité des caractères phénotypiques chez les arbres forestiers. Genet. Sel. Evol., 26(1): 105s-123s.

Li, C., 2000. RAPD analysis of genetic variation in Eucalyptus microtheca F. Muell. populations. Hereditas, 132(2): 151-156.

Mohammadi, S.A., Prasanna, B.M., 2003. Analysis of genetic diversity in crop plants salient statistical tools and considerations. Crop Sci., 43(4): 12351248 .

Nei, M., 1987. Molecular evolutionary genetics. Columbia University Press, New York, USA, p.512.

Ojuederie, O., Igwe, D., Okuofu, S., Faloye, B., 2013. Assessment of Genetic Diversity in Some Moringa oleifera Lam. Landraces from Western Nigeria Using RAPD Markers. Afr. J. Plant Sci. Biotechnol., 7(1): 15-20.

Olawuyi, O., Azeez, A., 2019. Molecular evaluation of Garcinia kola Heckel accessions using RAPD markers. Am. J. Mol. Biol., 9: 41-51.

Porras-Hurtado, L., Ruiz, Y., Santos, C., Phillips, C., Carracedo, A., Lareu, M.V., 2013. An overview of STRUCTURE: applications, parameter settings, and supporting software. Front. Genet., 4(98): 1-13.

Pritchard, J.K., Stephens, Donnelly, P., 2000. Inference of population structure using multilocus genotype data. Genetics, 155: 945-959.

Seyit, A., Erdogan, E., Emine, P., 2010. Comparison of Effectiveness of ISSR and RAPD Markers in 
Genetic Characterization of Seized Marijuana, Cannabis sativa L. in Turkey. Afr. J. Agric. Res., 5(21): 2925-2933.

Song, Z.P., Li, B., Chen, J.K., Lu, B.R., 2005. Genetic diversity and conservation of common wild rice (Oryza rufipogon) in China. Plant Species Biol., 20(2): 83-92.

Tharachand, C., Selvaraj, C., Immanuel, Abraham, Z., 2015. Molecular Insights into the Genetic Diversity of Garcinia cambogia Germplasm Accessions. Braz. Arch. Biol. Technol., 58(5): 765-772.

Utpala, P., Nandakishore, O., Nirmalbabu, K., Kumar, S., Parthasarathy, V., 2013. Comparative effectiveness of inter-simple sequence repeat and randomly amplified polymorphic DNA markers to study genetic diversity of Indian Garcinia. Afr. J. Biotechnol., 12(46): 6443-6451.

Vicente, M.C., Fulton, T., 2003. Using molecular marker technology in studies on plant genetic diversity studies: Learning module. International Plant Genetic Resources Institute (IPGRI), Rome, Italy, p.194.

Vroh, B.I., du Jardin, P., Mergeai, G., Baudoin, J.P., 1997. Optimisation et application de la RAPD (Random Amplified Polymorphic DNA) dans un programme de sélection récurrente chez le cotonnier (Gossypium spp.). Biotechnol. Agron. Soc. Environ., 1(2): 142-150.

Weir, B.S., Cockerham, C.C., 1984. Estimating Fstatistics for analysis of population structure. Evolution, 38(6): 1358-1370.

Watts, P.C., Kemp, S.J., Saccheri, I.J., Thompson, D.J., 2005. Conservation implications of genetic variation between spatially and temporally distinct colonies of the endangered damselfly Coenagrion mercuriale. Ecol. Entomol., 30: 541-547.

Williams, J.G., Kubelik, A.R., Livak, K.J., Rafalski, J.A., Tingey, S.V., 1990. DNA polymorphisms amplified by arbitrary primers are useful as genetic markers. Nucleic Acids Res., 18(22): 6531-6535.

Wright, S., 1951. The genetical structure of populations. Ann Eugen., 15(4): 323-354.

Wright, S., 1978. Evolution and the genetics of populations. Volume 4: Variability within and among Natural Populations. University of Chicago Press, Chicago, USA, p.590.

Yeh, F.C., Chong, D.K., Yang, R.C., 1995. RAPD variation within and among natural populations of trembling aspen (Populus tremuloides Michx.) from Alberta. J. Hered., 86(6): 454-460.

\section{How to cite this article:}

Koffi, K. K., Komenan, A. O., Goba, K. A. E., Zoro, B. I. A., 2022. Structure and genetic diversity of two populations of Garcinia kola Heckel (Clusiaceae) revealed by RAPD markers. Int. J. Curr. Res. Biosci. Plant Biol., 9(1): 32-41. doi: https://doi.org/10.20546/ijcrbp.2022.901.004 